\title{
Seleção de Basidiomycetes da Amazônia para produção de enzimas de interesse biotecnológico
}

\author{
Screening of basidiomycetes from Amazonia for the production of biotechnological interest enzymes
}

\author{
Helenires Queiroz de SOUZA ${ }^{1 *}$, Luiz Antonio de OLIVEIRA², Jerusa Souza ANDRADE ${ }^{3}$
}

\begin{abstract}
Resumo
Os fungos têm sido bastante usados como produtores de diferentes substâncias de interesse econômico, tais como: enzimas, antibióticos, vitaminas, aminoácidos e esteróides. Este estudo teve como objetivo detectar a produção de enzimas por linhagens de Basidiomycetes, oriundas de áreas de floresta da Amazônia. Para a produção de enzimas, os fungos foram cultivados em meio líquido adicionado de substrato indutor (0,5\%), pH ajustado para cada enzima e incubados a $28^{\circ} \mathrm{C}$, sob agitação a $140 \mathrm{rpm}$, durante 96 ou 120 horas. A massa micelial foi separada for filtração e os filtrados foram inoculados em cup plates de $6 \mathrm{~mm}$ de diâmetro, perfurados na superfície de meios de cultura sólidos, adequados para a detecção das enzimas amilases, proteases, celulases, fenoloxidases e pectinases em placa de Petri. As placas foram incubadas à temperatura de $28{ }^{\circ} \mathrm{C}$ por 24 horas, e reveladas para observação dos halos indicativos da atividade enzimática. Foi verificada também a atividade da amilase e protease produzida pelos fungos, crescidos em meio líquido, com diferentes fontes nutricionais. Foi possível detectar a produção de celulases e proteases por todos os isolados, $40 \%$ produziram amilases, $50 \%$ produziram fenoloxidases e $10 \%$ produziram pectinases. Quanto à atividade da amilase, o substrato farelo de trigo foi o que proporcionou os maiores halos de degradação, destacandose os fungos Daedalea sp. 4E6 e Daedalea sp. 1A, Stereaceae 22B e Pycnoporus sanguineus 12B. Considerando os substratos testados para produção de proteases, o substrato concentrado protéico de peixe se destacou como a melhor fonte protéica. Os fungos $P$. sanguineus $12 \mathrm{~B}$, Stereaceae 22B e Cantharellus guyanensis $4 \mathrm{Bl}$ foram os melhores produtores de protease.

Palavras-chave: atividade enzimática; fungos; biotecnologia.
\end{abstract}

\begin{abstract}
Mushrooms, edible basidiomycetes, have been extensively used as producers of different substances of economical interest, such as enzymes, antibiotics, vitamins, amino acids, and steroids. The objective of this study is to detect the production of enzymes such as amylases, proteases, cellulases, phenoloxidases and pectinases for lineages of basidiomycetes originating from the Amazonian forest. For the production of enzymes, mushrooms were cultivated in a liquid medium with substratum $(0,5 \%), \mathrm{pH}$ adjusted for each enzyme, and incubated at $28{ }^{\circ} \mathrm{C}$, under agitation and $140 \mathrm{rpm}$ for 96 or 120 hours. After this period, the samples were filtered for the separation of the mycelial mass. The filtrates were inoculated in solid medium surface perforated cup-plates of $6 \mathrm{~mm}$ diameter, appropriate for the detection of enzymes in Petri dishes. The plates were incubated at $28^{\circ} \mathrm{C}$ for 24 hours, for observation to reveal enzymatic halos. It was verified the activity of the amylase and protease produced by the mushrooms grown in the liquid medium, with different nutritive sources. It was possible to detect the cellulase and protease production for all the ones that were isolated, $40 \%$ produced amylases, $50 \%$ produced phenoloxidases, and $10 \%$ produced pectinases. Regarding the activity of the amylase, the wheat bran substrate presented the largest degradation halos revealing Daedalea sp.4E6 and Daedalea sp. 1A, Stereaceae 22B and Pycnoporus sanguineus 12B mushrooms. Considering the substrata tested for protease production, it was observed that the fish protein concentrate was the best. The P. sanguineus 12B, Stereaceae 22B and Cantharellus guyanensis $4 \mathrm{Bl}$ mushrooms were the best protease producers.
\end{abstract}

Keywords: enzymatic activity; mushrooms; biotechnology.

\section{Introdução}

A classe Basidiomycetes propriamente dita inclui os fungos em sua maioria saprófitos, que possuem basídios, corpos frutíferos que vão de alguns centímetros até quase um metro, todos visíveis a olho nu. A sistemática é feita pela morfologia do píleo, lamelas e poros (SILVEIRA, 1995).

Os fungos têm sido bastante usados como produtores de diferentes substâncias de interesse econômico, tais como: enzimas, antibióticos, vitaminas, aminoácidos e esteróides (BRAGA; DESTÉFANO; MESSIAS, 1999). As enzimas são usadas, em grande escala, na indústria de tecidos (celulases), detergentes (proteases e lipases), de alimentos (amilases, pectinases, proteases e celulases) e de couro (proteases e lipases) (NIELSEN; OXENBOLL, 1998).

Dentre as enzimas de importância industrial, produzidas por fungos, e de interesse na área de alimentos, foram abordadas neste trabalho as celulases, fenoloxidases, pectinases, amilases e proteases.

${ }^{1}$ Programa de Pós-Graduação em Biotecnologia, Universidade Federal do Amazonas - UFAM, E-mail: helenires@yahoo.com.br

${ }^{2}$ Coordenação de Pesquisas em Ciências Agronômicas, Instituto Nacional de Pesquisas da Amazônia - INPA

${ }^{3}$ Coordenação de Pesquisas em Tecnologia de Alimentos, Instituto Nacional de Pesquisas da Amazônia - INPA, Universidade Nilton Lins - UNINILTON LINS

${ }^{*}$ A quem a correspondência deve ser enviada 
As celulases são as enzimas mais utilizadas na indústria têxtil e de papel e celulose (BON; PEREIRA, 1999). Atuam na hidrólise de substratos celulósicos e compreendem um complexo de enzimas celulolíticas compostas por endoglucanase ou endo1,4 - $\beta$-glucanase, exoglucanase ou exo-1,4- $\beta$-glucanase, celobiase ou $\beta$-glucosidase e exoglucosidase ou exo-1,4- $\beta$-glucosidase (DA-SILVA, 1997).

Dentre as fenoloxidases estão as maiores famílias de enzimas fúngicas ligninolíticas como lacases, lignina peroxidase-LiP e manganês peroxidase-MnP (D'SOUZA; MERRIT; REDDY, 1999). Os mais efetivos biodegradadores de lignina na natureza são os fungos da podridão branca, pertencentes aos basidiomicetos. A maioria produz lacase, fenoloxidase extracelular com importante papel na degradação da lignina. Estas enzimas são utilizadas principalmente na indústria de biopolpação da madeira, aproveitamento de resíduos lignocelulósicos para ração animal, degradação de xenobióticos e biorremediação (VALMASEDA; ALMENDROS; MARTÍNEZ, 1990; BANERJEE; VOHRA, 1991; MATHEUS; OKINO, 1998; D'SOUZA; MERRIT; REDDY, 1999).

$\mathrm{Na}$ indústria de alimentos, as pectinases são usadas na clarificação de sucos de frutas, reduzindo a viscosidade e eliminando a turbidez (BON; PEREIRA, 1999). As pectinases catalisam a degradação de substâncias pécticas e apesar da pectina conter outros açúcares em sua constituição, normalmente o termo pectinase se refere às enzimas que degradam moléculas constituídas por unidades de ácidos galacturônicos (DA-SILVA; FRANCO, 1997). As pectinases são classificadas em despolimerizantes (poligalacturonase, exo-poligalacturonase, pectina-liase, pectato-liase) e desmetoxilantes (pectinesterase).

As amilases formam o principal grupo de enzimas utilizado na indústria de alimentos, principalmente em panificação e biscoitaria (BON; PEREIRA, 1999). As amilases hidrolisam os amidos e são classificadas em várias formas, dependendo de como atuam sobre as moléculas de amido. $\mathrm{O}$ amido é composto de dois glucanos, a amilose linear, contendo unidades de D-glicose unidas por ligações $\alpha$ (1-4), e a amilopectina ramificada, que consiste de resíduos de D-glicose unidos por ligações $\alpha$ (1-4) contendo, além disso, ramificações formadas por ligações $\alpha$ (1-6) (FRAZIER; WESTHOFF, 1988). Quanto à natureza das ligações hidrolisadas, as amilases podem ser reunidas em cinco classes, $\alpha$-amilases, $\beta$-amilases, isoamilases, glucoamilases, ciclodextrina-glucanotransferase (CORNELIS, 1987).

As proteases ou enzimas proteolíticas são usadas em processos industriais de tratamento de couro e peles, na formulação de detergentes, na indústria de alimentos, assim como na panificação, juntamente com as amilases, sendo responsáveis pela hidrólise do glúten e no processamento de carnes, conservas e peixes (BON; PEREIRA, 1999). Incluem as proteinases, as quais catalisam a hidrólise da molécula de proteína em fragmentos grandes, e as peptidases, que hidrolisam estes fragmentos de polipeptídeos até chegarem a aminoácidos (FRAZIER; WESTHOFF, 1988).

Desta forma, este estudo teve como objetivos detectar a produção de enzimas, como amilases, proteases, celulases, fenoloxidases e pectinases por linhagens de Basidiomycetes isoladas de áreas de floresta na Amazônia; e verificar a atividade da amilase e da protease produzida pelos fungos crescidos em meio líquido com diferentes fontes de carbono e proteína.

\section{Material e métodos}

\subsection{Material biológico}

\section{Coleta dos Basidiomycetes}

Os fungos foram coletados na Reserva de Campina do INPA, localizada na BR 174, Km 45, na mata do minicampus universitário da UFAM, no Bosque da Ciência do INPA, no campus do INPA/V8 e em Urucu, município de Coari-AM. Os espécimes foram coletados com auxílio de canivete, removendose parte do substrato, e foram acondicionados em recipientes plásticos ou sacos de papel (SOUSA, 1980). Uma parte do material coletado foi utilizada para o isolamento micelial e a outra foi reservada para a identificação taxonômica.

\section{Análise morfológica dos espécimes}

O trabalho foi desenvolvido no Laboratório de Microbiologia do Solo (CPCA) do INPA (Instituto Nacional de Pesquisas da Amazônia). A análise do basidioma dos fungos foi realizada com auxílio de microscópio estereoscópico Lambda (LEB-2). Nos fungos ainda frescos foram observadas características do píleo e estipe (coloração, forma, consistência, himenóforo, volva, anel e véu). As medidas foram realizadas com régua milimetrada. Após anotar as características do material fresco, este foi seco em estufa com temperatura entre $50-60^{\circ} \mathrm{C}$. Foram preparados cortes do material à mão livre, utilizando-se lâmina inoxidável, sob estereomicroscópio. Foram utilizadas solução de KOH 3\%, reagente de Melzer e Azul de Algodão para verificar as reações de mudança de cor, amiloidia e cianofilia de micro estruturas como basidiósporos e hifas (MARTIN, 1934; KOTABLA; POUZAR, 1964; SINGER, 1986). A observação das microestruturas foi realizada em microscópio binocular Zeiss West Germany. A terminologia micológica seguiu os trabalhos de Snell e Dick (1957) e Fidalgo e Fidalgo (1967), e a identificação dos fungos seguiu os trabalhos de Dennis (1970) e Silveira (1995).

\section{Isolamento micelial}

Foi selecionado um exemplar de boa qualidade, o qual foi lavado, primeiramente, em água corrente. Em câmara de fluxo laminar foi lavado com água destilada e mergulhado por um minuto em uma solução de hipoclorito de sódio: água destilada (1:10) (BONONI; TRUFEM, 1985), sendo então lavado com álcool etílico em placa de Petri.

Para obtenção da cultura do fungo, os esporos ou fragmentos do tecido vivo (cogumelo ou orelha de pau) foram retirados com pinça e colocados em placas de Petri contendo meio de cultura BDA (caldo de $200 \mathrm{~g}$ de batata; 20 g. $\mathrm{L}^{-1}$ de dextrose; 15 g. $\mathrm{L}^{-1}$ de ágar, completando para $1000 \mathrm{~mL}$ com água destilada), acrescido de antibiótico (100 $\mu$ g. $\mathrm{mL}^{-1}$ de terramicina) e incubado a $28^{\circ} \mathrm{C}$ por 7 a 10 dias, quando ocorreu o desenvolvimento do micélio. Fragmentos do micélio da cultura obtidos foram 
transferidos para tubos de ensaio contendo meio de cultura inclinado BDA, e foram preservados sob refrigeração a $4{ }^{\circ} \mathrm{C}$ (BONONI; TRUFEM, 1985; CORNELIS, 1987).

\subsection{Detecção da produção de enzimas}

\section{Condições de cultivo para produção de enzimas}

Para a produção de enzimas, os fungos testados foram previamente cultivados em meio BDA (batata dextrose ágar) por 10 dias. Três discos de micélio das espécies de Basidiomycetes foram cultivados em meio líquido Solução de Manachini $\left(\mathrm{KH}_{2} \mathrm{PO}_{4}, 2\right.$ g.L. $\mathrm{L}^{-1} ;\left(\mathrm{NH}_{4}\right)_{2} \mathrm{SO}_{4}, 1$ g.L. $\mathrm{L}^{-1} ; \mathrm{MgSO}_{4} \cdot 7 \mathrm{H}_{2} \mathrm{O}, 0,1 \mathrm{~g} . \mathrm{L}^{-1}$; $\mathrm{Na}_{2} \mathrm{HPO}_{4} \cdot 2 \mathrm{H}_{2} \mathrm{O}, 0,9$ g.L.- ${ }^{-1}$; extrato de levedura, 1 g.L. $\mathrm{L}^{-1}$; água destilada, $1000 \mathrm{~mL}$ ), adicionado de substrato indutor (0,5\%), e pH ajustado para cada enzima: amilase (amido de milho Maizena ${ }^{\circ}$, pH 6,0); celulase (carboximetilcelulose ou CMC Fluka, pH 5,0); pectinase (pectina cítrica Vetec, $\mathrm{pH} 2,5$ ); protease (gelatina, $\mathrm{pH}$ 6,9); fenoloxidase (farelo de trigo, pH 6,0). A incubação foi conduzida a $28^{\circ} \mathrm{C}$, sob agitação a $140 \mathrm{rpm}$, durante 96 ou 120 horas (MANACHINI; FORTINA; PARINI, 1987; TEIXEIRA, 1994) e o experimento foi realizado em triplicata.

\section{Ensaio qualitativo cup plate para detecção de enzimas}

Após o período de incubação em meio líquido, as amostras foram filtradas com gaze esterilizada, para a separação da massa micelial. Quantidades de $100 \mu \mathrm{L}$ do filtrado foram inoculadas em cup plates de $6 \mathrm{~mm}$ de diâmetro perfurados na superfície de meios de cultura sólidos adequados para a detecção de cada enzima em placa de Petri.

Para amilase foi utilizado ágar-amido (ágar, 18 g.L $\mathrm{L}^{-1}$; amido, 10 g. $\mathrm{L}^{-1}$, tampão citato-fosfato $0,1 \mathrm{M}, \mathrm{pH} 5,0$ ). Para celulase, ágar-CMC (ágar, 18 g.L $\mathrm{L}^{-1}$, carboximetilcelulose, 10 g.L. $\mathrm{L}^{-1}$, tampão acetato de $\mathrm{Na}^{+} 0,1 \mathrm{M}, \mathrm{pH} 5,0$ ). Para pectinase, ágar-pectina (ágar, 18 g.L.- , pectina, 10 g. $\mathrm{L}^{-1}$, tampão acetato de $\mathrm{Na}^{+} 0,1 \mathrm{M}$, $\mathrm{pH} 5,0$ ). Para protease, ágar-gelatina-leite (ágar, $18 \mathrm{~g} . \mathrm{L}^{-1}$, solução de gelatina $10 \%$, solução de leite desnatado $10 \%$, tampão citrato fosfato $0,1 \mathrm{M}, \mathrm{pH} 5,0)$. Para fenoloxidase, ágar-ácido tânico (ágar, 18 g.L $\mathrm{L}^{-1}$, ácido tânico 0,5\%, tampão citrato fosfato $0,1 \mathrm{M}, \mathrm{pH} 5,0)$.

As placas foram incubadas à temperatura de $28^{\circ} \mathrm{C}$ por 24 horas. Após este período, foram reveladas com iodo $0,1 \mathrm{~N}$ (amilase), vermelho do Congo 0,1\% (celulase) e ácido clorídrico $5 \mathrm{~N}$ (pectinase). A produção das enzimas foi observada pela formação dos halos enzimáticos, os quais foram medidos com paquímetro e os resultados expressos em mm (DINGLE; REID; SOLOMONS, 1953, TEIXEIRA, 1994). O ensaio foi realizado em triplicata.

\subsection{Atividade da amilase e da protease}

\section{Crescimento em meio líquido}

Para a produção de amilases, os fungos estudados foram previamente cultivados em meio BDA por 10 dias. Três discos de micélio das espécies de Basidiomycetes foram cultivados em frascos de $125 \mathrm{~mL}$ contendo $50 \mathrm{~mL}$ de meio líquido $\left(\mathrm{KH}_{2} \mathrm{PO}_{4}\right.$,
5 g.L $\mathrm{L}^{-1} ; \mathrm{K}_{2} \mathrm{HPO}_{4}, 6,7$ g.L.- ${ }^{-1}\left(\mathrm{NH}_{4}\right)_{2} \mathrm{SO}_{4}, 1$ g.L $\mathrm{L}^{-1} ; \mathrm{MgSO}_{4} \cdot 7 \mathrm{H}_{2} \mathrm{O}$, $0,1 \mathrm{~g} . \mathrm{L}^{-1}$; Âgua destilada, $1000 \mathrm{~mL}, \mathrm{pH} 7,0$ ) e diferentes fontes de carbono como amido de milho, maltose ou farelo de trigo, todos na proporção de $40 \mathrm{~g} . \mathrm{L}^{-1}$. A incubação ocorreu em temperatura de $28^{\circ} \mathrm{C}$, sob agitação de $140 \mathrm{rpm}$, durante 96 horas. A centrifugação (mini centrífuga Mini Spin Eppendorf) foi a 9000 rpm por 15 minutos. O sobrenadante foi usado como caldo enzimático bruto (SIQUEIRA; MIZUTA; GIGLIO, 1997).

Para produção de proteases, os fungos estudados foram previamente cultivados em meio BDA por 10 dias. Três discos de micélio das espécies de Basidiomycetes foram cultivados em frascos de $125 \mathrm{~mL}$ contendo $50 \mathrm{~mL}$ de meio líquido Solução de Manachini, adicionados de diferentes fontes de proteína (gelatina, concentrado protéico de peixe, farinha de soja, todos a 5 g.. $\left.\mathrm{L}^{-1}\right)$. Após a incubação a $28^{\circ} \mathrm{C}$, sob agitação de $140 \mathrm{rpm}$, durante 96 horas, as amostras foram centrifugadas em mini centrífuga Mini Spin Eppendorf (9000 rpm por 15 minutos) e o sobrenadante foi usado como caldo enzimático bruto.

O substrato concentrado protéico de peixe ou "piracuí" (termo regional) foi obtido de pesquisas da Coordenação de Pesquisas em Tecnologia de Alimentos (CPTA/INPA). O piracuí é constituído de $73,52 \%$ de proteínas, $27,66 \%$ de lipídios, $1,66 \%$ de cinzas e $5,23 \%$ de umidade. Este substrato nada mais é que o filé de piranha, peixe da região, o qual foi triturado e seco, transformando-se em farinha.

\section{Detecção da produção de amilases e proteases em meio sólido}

O caldo enzimático bruto $(100 \mu \mathrm{L})$ obtido de cada amostra foi transferido para cup plates de $6 \mathrm{~mm}$ de diâmetro perfurados na superfície de meio de cultura sólido.

Para amilases, foi utilizado ágar-amido e para proteases ágar-gelatina-leite. As placas de Petri foram incubadas à temperatura de $28^{\circ} \mathrm{C}$ por 24 horas. Após este período, foram observadas quanto à formação dos halos enzimáticos. Os halos indicadores da produção de amilase são visualizados após a revelação com solução de iodo $0,1 \mathrm{~N}$, enquanto que os halos de produção de proteases podem ser observados sem a necessidade de um revelador. Os halos foram medidos com paquímetro e expressos em mm (DINGLE; REID; SOLOMONS, 1953; TEIXEIRA, 1994). O experimento foi realizado em triplicata.

Os resultados dos diâmetros dos halos enzimáticos da amilase e da protease foram analisados pelo teste de Tukey utilizando-se o programa ESTAT (Sistema para análises estatísticas, UNESP/Jaboticabal, versão 2.0).

\section{Resultados e discussão}

Foi coletado um total de 60 fungos da classe Basidiomycetes no período de fevereiro a junho de 2003. Destes, foram identificadas as ordens Agaricales, Aphyllphorales, Auriculariales e Tremellales, e as famílias Agaricaceae, Auriculariaceae, Cantharellaceae, Ganodermataceae, Hygrophoraceae, Polyporaceae, Russulaceae, Stereaceae, Tremellaceae e Tricholomataceae.

Dentre os fungos coletados, foram isolados exemplares dos gêneros Trametes, Pycnoporus, Ganoderma, Stereum, Daedalea, 
Cantharellus e Pleurotus, os quais foram utilizados nos ensaios enzimáticos.

\subsection{Deteç̧ão da produção de enzimas}

Com a técnica de cup plate foi possível detectar que todos os isolados produziram celulases e proteases, $40 \%$ produziram amilases, $50 \%$ produziram fenoloxidases e $10 \%$ pectinases (Figura 1 ).

Revelando-se as placas de ágar-CMC com corante Vermelho do Congo, a zona clara em forma de halos indica a ação enzimática da celulase, enquanto que a parte não afetada pela enzima cora-se de vermelho (MULLINGS, 1985).
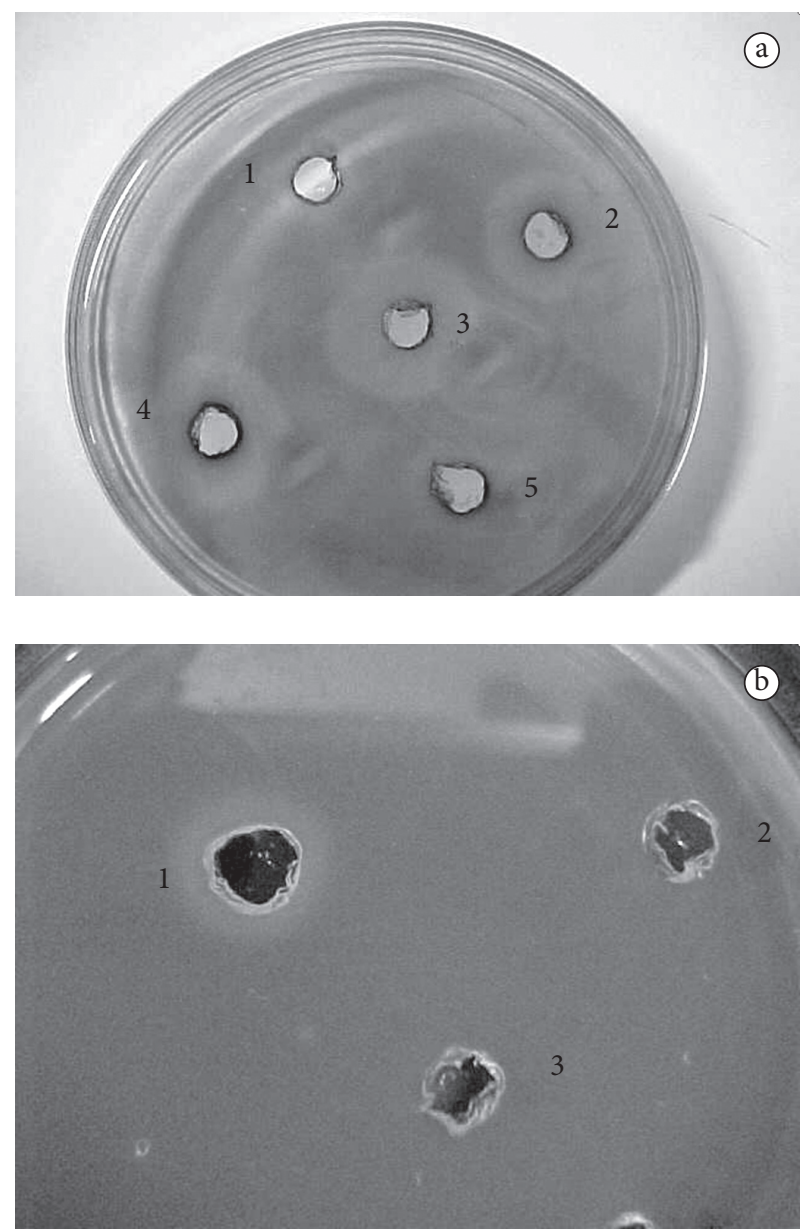

A produção de proteases pode ser observada nas placas de ágar-gelatina-leite sem a necessidade de um revelador e o resultado positivo surge na forma de halos claros.

As amilases podem ser visualizadas revelando-se as placas de ágar-amido com solução de iodo $1 \mathrm{~N}$, tintura de iodo ou vapor de cristais de iodo. $\mathrm{O}$ amido cora-se de azul e a área de degradação enzimática apresenta halos translúcidos.

As fenoloxidases podem ser observadas pela formação de halos de coloração marron, resultantes da oxidação do ácido tânico presente no ágar pela ação das enzimas como lacases, manganês-peroxidases e lignina-peroxidases.


(e)

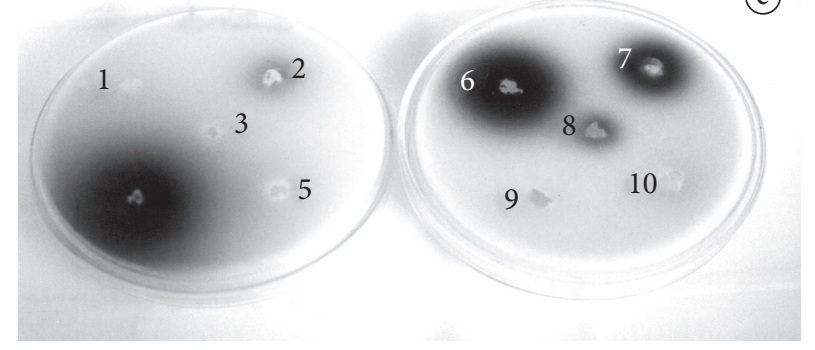

Figura 1. Detecção de enzimas produzidas por Basidiomycetes: a) Celulases; b) Pectinases; c) Proteases; d) Amilases; e e) Fenoloxidases. 
As pectinases são observadas nas placas com ágar-pectina pelo surgimento de um halo opaco ao redor do cup plate após a revelação com $\mathrm{HCl} 5 \mathrm{~N}$.

A Tabela 1 apresenta os dados da produção enzimática dos Basidiomycetes ensaiados. Todos foram capazes de produzir pelo menos duas das enzimas estudadas. Os maiores halos para protease foram apresentados por $P$. sanguineus $12 \mathrm{~B}$ e G. applanatum 15B2. Para amilases, foram obtidos os maiores halos pelos isolados Trametes sp. 11E4 e Stereum sp. 6D2. Quanto à produção de fenoloxidases, 50\% dos fungos produziram este grupo de enzimas, destacando-se P. sanguineus $12 \mathrm{~B}$ com halo de 17,87 mm. Todos os fungos estudados foram capazes de produzir celulases, destacando-se o isolado Trametes sp. 11E4. Foi detectada a produção de pectinases apenas para P. sanguineus.

Todos os fungos testados foram capazes de produzir proteases. Os halos variaram de 10,56 $\mathrm{mm}$ de diâmetro para Stereum sp. até 23,78 mm para Pycnoporus sanguineus 12B.

Alves et al. (2002) verificaram a produção de proteases por diferentes espécies de Mucor spp. cultivadas em meio sólido durante 96 horas. As colônias apresentaram halos que variaram de 3 a $6,4 \mathrm{~cm}$.

Proteases são produzidas por vários microrganismos, como vírus, bactérias, protozoários e fungos. As proteases de origem microbiana correspondem a cerca de $40 \%$ da venda total mundial de enzimas. Possuem a maioria das características desejadas para aplicação em biotecnologia, e seu custo de produção é menor do que para enzimas de origem vegetal ou animal (SAID; PIETRO, 2002).

As enzimas proteolíticas, proteases ou proteinases pertencem ao grupo das hidrolases, as quais têm em comum o envolvimento da água na formação do produto. Estas enzimas catalisam a reação de hidrólise das ligações peptídicas das proteínas, ocorrendo a transferência de componentes do substrato para a água (WHITAKER, 1994). O principal papel das enzimas proteolíticas é nutricional, em que grandes cadeias polipeptídicas são hidrolisadas em pequenas moléculas que a célula possa absorver (FEDATTO, 2004).

Foi possível detectar a produção de amilases pelos fungos P. sanguineus 12B, Ganoderma sp. 2A2, Trametes sp. 11E4 e Stereum sp. 6D2. Os halos variaram de 7,0 a 17,53 mm de diâmetro.

As amilases são enzimas que hidrolisam moléculas de amido para formar diversos produtos incluindo dextrinas e polímeros menores compostos de moléculas de glicose (REDDY; NIMMAGADDA; RAO, 2003). Estas enzimas constituem uma classe de enzimas industriais com aproximadamente $25 \%$ do mercado de enzimas (SINDHU et al., 1997; RAO et al., 1998).

El-Zalaki e Hamza (1979) estudaram cinco variedades de cogumelos, Absidia blakesleeana, Agaricus bisporus (Lange) Imbach, Lentinus edodes, Peziza auburouniv e Polyporus sulphureus (Bull.: Fr.) Fr., quanto à habilidade em hidrolisar $\mathrm{o}$ amido. $\mathrm{O}$ fungo $L$. edodes foi a linhagem mais promissora para produção de amilases, a atividade amilolítica atingiu seu máximo (621 U.mL $\mathrm{mL}^{-1}$ ) após sete dias de incubação.

Foi verificada a produção de amilases por espécies de Mucor spp. crescidas em meio sólido acrescentado de amido solúvel. Após 72 horas de incubação, foram visualizados halos de 4,6 a 8,5 cm de diâmetro (ALVES et al., 2002).

Quanto à produção de fenoloxidases, os diâmetros dos halos variaram de $10,44 \mathrm{a} 17,87 \mathrm{~mm}$, destacando-se o fungo $P$. sanguineus $12 \mathrm{~B}$.

Os fungos capazes de produzir fenoloxidases foram $P$. sanguineus $12 \mathrm{~B}$, Stereaceae $22 \mathrm{~B}$, C. guyanensis $4 \mathrm{BL}$, Daedalea sp. 1A e Daedalea sp. 4E6.

As fenoloxidases estão amplamente distribuídas em muitas espécies de plantas e fungos (ROBLES et al., 2000).

Vários trabalhos de screening de enzimas ligninolíticas têm sido realizados principalmente com fungos Basidiomycetes da podridão branca. Entretanto, outros fungos, representantes de diferentes grupos taxonômicos e ecofisiológicos são capazes de degradar substratos lignocelulósicos e produzir enzimas ligninolíticas (SAPARRAT et al., 2002).

A degradação da lignina é um processo complexo envolvendo vários tipos de enzimas oxidantes: 1) Lignina peroxidases catalizam a quebra de cadeias de arilpropano, pontes de éter e abertura de anéis aromáticos; 2) Manganês peroxidases oxidam os componentes fenólicos da lignina em um processo

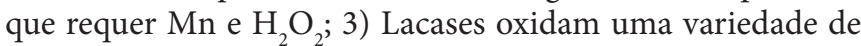

Tabela 1. Atividade de enzimas de Basidiomycetes da Amazônia: média de diâmetros de halos (mm) em meio sólido.

\begin{tabular}{|c|c|c|c|c|c|}
\hline \multirow[t]{2}{*}{ Isolados } & \multicolumn{5}{|c|}{ Enzimas (halos em mm) } \\
\hline & Proteases ${ }^{*}$ & Amilases $^{* *}$ & Celulases $^{* *}$ & Fenoloxidases ${ }^{*}$ & Pectinases $^{* *}$ \\
\hline Trametes sp. 11E4 & $10,9^{\mathrm{F}}$ & $17,5^{\mathrm{A}}$ & $21,4^{\mathrm{A}}$ & 0 & 0 \\
\hline Ganoderma sp. 2A2 & $12,9^{\mathrm{E}}$ & $7,0^{\mathrm{C}}$ & $13,4^{\mathrm{B}}$ & 0 & 0 \\
\hline Pycnoporus sanguineus 12B & $23,8^{\mathrm{A}}$ & $9,0^{\mathrm{B}}$ & $18,6^{\mathrm{A}}$ & $17,9^{\mathrm{A}}$ & $13,03^{\mathrm{A}}$ \\
\hline Stereum sp. 6D2 & $10,5^{\mathrm{F}}$ & $17,0^{\mathrm{A}}$ & $20,1^{\mathrm{A}}$ & 0 & 0 \\
\hline Stereaceae 22B & $17,2^{\mathrm{CD}}$ & 0 & $13,4^{\mathrm{B}}$ & $12,5^{\mathrm{BC}}$ & 0 \\
\hline Daedalea sp. 1A & $18,7^{\mathrm{BC}}$ & 0 & $19,6^{\mathrm{A}}$ & $10,7^{\mathrm{C}}$ & 0 \\
\hline Pleurotus sp. 1C4 & $15,9^{\mathrm{D}}$ & 0 & $20,4^{\mathrm{A}}$ & 0 & 0 \\
\hline Daedalea sp. 4E 6 & $18,2^{\mathrm{BC}}$ & 0 & $19,5^{\mathrm{A}}$ & $11,9^{\mathrm{B}}$ & 0 \\
\hline Cantharellus guyanensis 4Bl & $18,7^{\mathrm{BC}}$ & 0 & $10,6^{\mathrm{B}}$ & $10,4^{\mathrm{BC}}$ & 0 \\
\hline G. applanatum 15B2 & $19,9^{\mathrm{B}}$ & 0 & $12,0^{\mathrm{B}}$ & 0 & 0 \\
\hline
\end{tabular}

As médias seguidas da mesma letra não diferem significativamente pelo teste de Tukey a 1\%; *96 horas de incubação; $\mathrm{e}^{\star *} 120$ horas de incubação. 
compostos fenólicos num processo que não requer peróxido de hidrogênio ou íons de manganês; e 4) outras enzimas como oxidases fornecem $\mathrm{H}_{2} \mathrm{O}_{2}$.

Todos os fungos estudados foram capazes de produzir celulases. O diâmetro dos halos variou de $10,65 \mathrm{~mm}$ para C. guyanensis até $20,43 \mathrm{~mm}$ para Pleurotus sp.

$\mathrm{Na}$ indústria alimentícia, as celulases são usadas em vários processos, principalmente na extração de componentes do chá verde, proteína de soja, óleos essenciais, aromatizantes e amido de batata-doce (ORBERG, 1981). A celulose, dentre os materiais naturais, é o biopolímero mais abundante do mundo e pode ser hidrolisada, com ácidos, à glicose. A hidrólise da celulose por celulases resulta na produção final de glicose (BAYER; LAMED, 1992).

As enzimas celulolíticas de fungos têm sido estudadas devido o seu potencial em biotecnologia, incluindo uso em alimentos e bebidas, detergente, indústria têxtil, polpa e papel. Sua função nutricional é evidente para a degradação da fibra vegetal servindo como fonte de carbono. Em geral, fungos celulolíticos produzem um grande número de celulases e muitos as usam para degradação de polissacarídeos da parede celular vegetal (DEHORITY, 1991).

Quanto à produção de pectinases, foi detectada a presença da enzima em meio sólido, apenas para $P$. sanguineus, com média de halo de 13,03 $\mathrm{mm}$.

Espécies de Mucor spp. são capazes de produzir pectinases em meio sólido acrescentado de pectina cítrica. Após 72 horas de crescimento das colônias, foram observados halos de 3,7 a $8,8 \mathrm{~cm}$ (ALVES et al., 2002).

Antov e Pericin (2001) apontam a habilidade do Basidiomycetes Polyporus squamosus (Hudson: Fr.) Fries em crescer e produzir pectinases em meio aquoso de duas fases composto de polietileno glicol e dextrana bruta. $\mathrm{O}$ fungo foi capaz de produzir simultaneamente dois produtos: as pectinases e a biomassa, como fonte de proteína para nutrição animal, quando em cultivo submerso.

Pectinases compreendem um grupo heterogêneo de enzimas que catalizam a quebra de substratos contendo pectina. As pectinases de fungos são enzimas extracelulares que degradam substâncias pécticas e possuem aplicação considerável na indústria de utilização de frutas. Atualmente, a aplicação de enzimas pectinolíticas desempenha um importante papel na tecnologia de alimentos para a maceração de frutos e vegetais, bem como para a extração, concentração e clarificação de sucos, para dar estabilidade ao néctar de frutas. Na produção industrial de sucos de frutas é necessário eliminar a pectina liberada durante o processamento da fruta para reduzir o tempo de filtração e aumentar a produção ao término do processo (SOUZA et al., 2003).

\subsection{Atividade da amilase}

Na Tabela 2 são apresentados os valores dos halos enzimáticos produzidos pela amilase dos Basidiomycetes cultivados em variadas fontes de carbono.
Quando o amido de milho foi utilizado como fonte de carbono, foi detectada a produção de amilases em sete isolados. Os halos enzimáticos variaram de 6,20 a 22,30 mm de diâmetro, sendo que os fungos Daedalea sp. 4E6 e Daedalea sp. 1A apresentaram os maiores halos estatisticamente. Não foi detectada a produção de amilases pelos fungos G. applanatum 15B2, Ganoderma sp. 2A2 e C. guyanensis 4Bl.

O substrato farelo de trigo, como fonte de carbono, induziu a produção de amilases por seis isolados. Os diâmetros dos halos variaram de 11,70 a $27,50 \mathrm{~mm}$, destacando-se os fungos Daedalea sp. 4E6. Estes, junto aos fungos Daedalea sp. 1A, Stereaceae 22B e P. sanguineus 12B foram considerados, estatisticamente, bons produtores da enzima. Não houve detecção de amilase nos outros isolados.

Seis isolados apresentaram produção de amilases quando a maltose foi utilizada como fonte de carbono. Os halos variaram de 11,60 a $16,70 \mathrm{~mm}$ de diâmetro e não diferiram estatisticamente. Os fungos $P$. sanguineus 12B, Stereum sp. 6D2, G. applanatum 15B2 e C. guyanensis $4 \mathrm{Bl}$ não apresentaram produção de amilase.

Sugere-se que a produção da enzima seja regulada pela fonte de carbono ou substrato utilizado.

Considerando a preferência dos fungos pelos três substratos testados, o amido de milho e o farelo de trigo proporcionaram os melhores resultados para o fungo Daedalea sp. 4E6. Por outro lado, os isolados Daedalea sp. 1A e Trametes sp. 11E4 apresentaram-se bem nos três substratos. O fungo Stereaceae 22B foi melhor em farelo de trigo. O isolado Pleurotus sp. 1C4 teve preferência pelo farelo de trigo e maltose. P. sanguineus $12 \mathrm{~B}$ foi melhor em farelo de trigo do que em amido, sendo que em maltose não produziu a enzima.

Foi verificado que as amilases produzidas pelos fungos crescidos em meio líquido acrescentado de farelo de trigo proporcionaram os maiores halos de degradação do amido (Tabela 2).

\subsection{Atividade da protease}

Os diâmetros dos halos enzimáticos das proteases produzidas pelos Basidiomycetes são apresentados na Tabela 3.

Considerando os três substratos testados, gelatina, farelo de soja e concentrado de peixe, para produção de proteases, foi observado que o substrato concentrado de peixe foi o melhor, proporcionando halos com média de $12,96 \mathrm{~mm}$ de diâmetro. O segundo melhor substrato foi a gelatina, com média de halo de $11,20 \mathrm{~mm}$.

Dos dez fungos testados, P. sanguineus e Stereaceae 22B foram considerados os melhores produtores de protease, com média de halos de 17,15 e 18,01 mm de diâmetro, respectivamente. C. guyanensis ficou em segundo lugar, obtendo a média de halos de 14,74 mm, seguido de Stereum sp. com média de 13,48 mm de diâmetro.

Quando a gelatina foi utilizada como substrato, Stereaceae $22 \mathrm{~B}$ e $P$. sanguineus foram considerados os melhores produtores de protease, com halos de 18,07 e 16,79 mm de diâmetro, respec- 
Tabela 2. Médias dos diâmetros dos halos $(\mathrm{mm})$ enzimáticos de amilases produzidas por Basidiomycetes cultivados em diferentes fontes de carbono.

\begin{tabular}{|c|c|c|c|c|}
\hline \multirow[t]{2}{*}{ Isolados } & \multicolumn{3}{|c|}{ Fonte de carbono } & \multirow[t]{2}{*}{ Média } \\
\hline & Amido & Farelo de trigo & Maltose & \\
\hline Daedalea sp. 4E6 & $22,3^{\mathrm{Aa}}$ & $27,5^{\text {Aa }}$ & $14,1^{\mathrm{Ab}}$ & $21^{\mathrm{A}}$ \\
\hline Daedalea sp. 1A & $19,7^{\mathrm{ABa}}$ & $23,1^{\mathrm{ABa}}$ & $16,7^{\text {Aa }}$ & $20^{\mathrm{AB}}$ \\
\hline Stereaceae 22B & $13,2^{\mathrm{BCb}}$ & $21,9^{\mathrm{ABa}}$ & $11,6^{\mathrm{Ab}}$ & $16^{\mathrm{BC}}$ \\
\hline Pleurotus sp. 1C4 & $10,8^{\mathrm{Cb}}$ & $17,7^{\mathrm{BCa}}$ & $11,6^{\mathrm{Aab}}$ & $13^{\mathrm{CD}}$ \\
\hline Pycnoporus sanguineus 12B & $10,5^{\mathrm{Cb}}$ & $19,1^{\mathrm{ABCa}}$ & 0 & $10^{\mathrm{DE}}$ \\
\hline Trametes sp. 11E4 & $8,7^{\mathrm{CDa}}$ & $11,7^{\mathrm{Ca}}$ & $12,8^{\mathrm{Aa}}$ & $11^{\mathrm{CD}}$ \\
\hline Stereum sp. 6D2 & $6,2^{\mathrm{CDa}}$ & 0 & 0 & $2^{\mathrm{F}}$ \\
\hline Ganoderma applanatum 15B2 & 0 & 0 & 0 & 0 \\
\hline Ganoderma sp. 2A2 & 0 & 0 & $14,7^{\mathrm{Aa}}$ & $5^{\mathrm{EF}}$ \\
\hline Cantharellus guyanensis $4 \mathrm{BL}$ & 0 & 0 & 0 & 0 \\
\hline Média & $9,2^{\mathrm{b}}$ & $12,1^{\mathrm{a}}$ & $8,1^{\mathrm{b}}$ & 10 \\
\hline
\end{tabular}

As médias seguidas de mesma letra maiúscula, na vertical, ou minúscula na horizontal, não diferem significativamente pelo teste de Tukey a $1 \%$.

Tabela 3. Médias dos diâmetros dos halos $(\mathrm{mm})$ enzimáticos de proteases produzidas por Basidiomycetes cultivados em diferentes fontes de proteína.

\begin{tabular}{|c|c|c|c|c|}
\hline \multirow[t]{2}{*}{ Isolados } & \multicolumn{3}{|c|}{ Fonte de proteína } & \multirow[t]{2}{*}{ Média } \\
\hline & Gelatina & Farelo de soja & Peixe & \\
\hline Stereum sp. 6D2 & $14,11^{\mathrm{BCa}}$ & $12,61^{\mathrm{Ba}}$ & $13,70^{\mathrm{Ba}}$ & $13,48^{\mathrm{BC}}$ \\
\hline Trametes sp. 11E4 & 0 & 0 & 0 & 0 \\
\hline Cantharellus guyanensis 4BL & $13,09^{\mathrm{Cb}}$ & $19,11^{\mathrm{Aa}}$ & $12,00^{\mathrm{BCb}}$ & $14,74^{\mathrm{B}}$ \\
\hline Ganoderma applanatum 15B2 & $13,53^{\mathrm{Ca}}$ & $11,33^{\mathrm{BCa}}$ & $12,74^{\mathrm{BCa}}$ & $12,30^{\mathrm{CD}}$ \\
\hline Pycnoporus sanguineus $12 \mathrm{~B}$ & $16,79^{\mathrm{ABa}}$ & $16,85^{\mathrm{Aa}}$ & $17,80^{\mathrm{Aa}}$ & $17,15^{\mathrm{A}}$ \\
\hline Ganoderma sp. 2A2 & 0 & 0 & 0 & 0 \\
\hline Daedalea sp. 1A & $11,56^{\mathrm{Cab}}$ & $9,60^{\mathrm{BCb}}$ & $12,99^{\mathrm{BCa}}$ & $11,39^{\mathrm{D}}$ \\
\hline Daedalea sp. 4E6 & $11,93^{\mathrm{Ca}}$ & $3,13^{\mathrm{Db}}$ & $11,87^{\mathrm{BCa}}$ & $8,97^{\mathrm{E}}$ \\
\hline Média & $11,20^{\mathrm{b}}$ & $9,94^{\mathrm{c}}$ & $12,96^{\mathrm{a}}$ & 11,30 \\
\hline
\end{tabular}

As médias seguidas de mesma letra maiúscula, na vertical, ou minúscula na horizontal, não diferem significativamente pelo teste de Tukey a $1 \%$.

tivamente. O segundo melhor foi Stereum sp., com 14,11 mm, seguido de C. guyanensis, G. applanatum, Pleurotus sp., Daedalea sp. $1 \mathrm{~A}$ e Daedalea sp. 4E6, que apresentaram resultados semelhantes.

Para o substrato farelo de soja, foi observada melhor produção de protease para C. guyanensis, Stereaceae 22B e $P$. sanguineus, com halos de 19,11, 17,33 e 16,85 mm de diâmetro, respectivamente. O fungo Stereum sp. foi o segundo melhor, com halo de $12,61 \mathrm{~mm}$, seguido de G. applanatum e Daedalea sp. $1 \mathrm{~A}$.

Os diâmetros dos halos da protease dos fungos cultivados em meio com concentrado de peixe variaram de 10,43 a $18,64 \mathrm{~mm}$. Os melhores produtores da enzima foram Stereaceae 22B e P. sanguineus com halos de 18,64 e 17,80 mm de diâmetro, respectivamente. Em seguida ficou o fungo Stereum sp., com halo de 13,70 $\mathrm{mm}$.

Considerando a afinidade de cada fungo por cada substrato testado, os fungos Stereum sp., G. applanatum, P. sanguineus e Stereaceae 22B apresentaram a mesma afinidade para os três substratos. O fungo C. guyanensis apresentou maior afinidade para farelo de soja. Pleurotus sp. teve maior afinidade por gelatina. Os fungos Daedalea sp. 4E6 e Daedalea sp. 1A optaram por gelatina e concentrado de peixe.

Os fungos Trametes sp. e Ganoderma sp. 2A2 não apresentaram halos enzimáticos, e também não mostraram crescimento micelial no meio de cultura líquido.

\section{Conclusões}

Todos os isolados de Basidiomycetes estudados foram capazes de produzir pelo menos duas das enzimas pesquisadas. Foi detectada pela técnica cup plate a produção de proteases e celulases por todos os fungos isolados. As espécies $P$. sanguineus, Ganoderma sp., Trametes sp. e Stereum sp. apresentaram resultados positivos para amilases. Os fungos Stereaceae 22B, P. anguineus, C. guyanensis, Daedalea sp. 1A e Daedalea sp. 4E6 formaram halos para a detecção de fenoloxidases. $\mathrm{O}$ isolado $P$. sanguineus produziu pectinases. 
As amilases produzidas pelos fungos, cultivados em meio líquido, acrescidos de farelo de trigo, proporcionaram os maiores halos de degradação do amido presente em meio sólido. Os fungos Daedalea sp. 4E6 e Daedalea sp. 1A, Stereaceae 22B e $P$. sanguineus $12 \mathrm{~B}$ produziram os maiores halos.

As proteases obtidas do cultivo dos fungos, em meio com concentrado de peixe, apresentaram os maiores halos enzimáticos em meio sólido. Os melhores produtores da enzima foram os fungos $P$. sanguineus $12 \mathrm{~B}$ e Stereaceae 22B.

\section{Agradecimentos}

Os autores agradecem à FAPEAM e à SUFRAMA pelo suporte financeiro.

\section{Referências bibliográficas}

ALVES, M. H. et al. Screening of Mucor sp. for the production of amylase, lipase, polygalacturonase and protease. Brazilian Journal of Microbiology, v. 33, n. 4, p. 325-330, 2002.

ANTOV, M. G.; PERICIN, D. M. Production of pectinases by Polyporus squamosus in aqueous two-phase system. Enzyme and Microbial Technology, v. 28, n. 4-5, p. 467-472, 2001.

BANERJEE, U. C.; VOHRA, R. M. Production of lacase by Curvularia sp. Folia Microbiol, v. 36, n. 4, p. 343-346, 1991.

BAYER, E. A.; LAMED, R. The cellulose paradox: pollutant par excellence and/or a reclaimable natural resource? Biodegradation, v. 3, n. 2-3, p. 171-188, 1992.

BON, E. P. S.; PEREIRA Jr., N. Tecnologia enzimática. Rio de Janeiro: E.P.S. Bon, 1999. 110 p.

BONONI, V. L. R.; TRUFEM, S. F. B. Cogumelos comestíveis. 2 ed. São Paulo: Editora Ícone, 1985. 83p.

BRAGA, G. U. L.; DESTÉFANO, R. H. R.; MESSIAS, C. L. Protease production during growth and autolysis of submerged Metarhizium anisopliae cultures. Revista de Microbiologia, v. 30, n. 2, p. 107-113, 1999.

CORNELIS, P. Microbial amylases. Microbiological Sciences, v. 4, n. 11, p. 342-343, 1987.

D SOUZA, T. M.; MERRIT, C. S.; REDDY, C. A. Lignin-modifying enzymes of the white rot basidiomycetes Ganoderma lucidum. Applied and environmental Microbiology, v. 65, n. 12, p. 5307-5313, 1999.

DA-SILVA, R.; FRANCO, C. M. L.; GOMES, E. Pectinases, hemicelulases e celulases, ação, produção e aplicação no processamento de alimentos: revisão. Boletim SBCTA, v. 31, n. 2, p. 249-260, 1997.

DEHORITY, B. A. Effects of microbial synergism on fibre digestion in the rumen. Proceedings of the Nutrition Society, v. 50, n. 2, p. 149-159, 1991.

DENNIS, R. W. G. Fungus flora of Venezuela and adjacent countries. Kew Bulletin Additional Series, London, v. 3, p. 531, 1970.

DINGLE, J.; REID, W. W.; SOLOMONS, G. L. The enzymic degradation of pectin and other polysaccharides. II Aplication of the "cupplate"assay to the estimation of enzymes. Journal of the Science of Food and Agriculture, v. 4, p. 149-155, 1953.

EL-ZALAKI, M. E.; HAMZA, M. A. Edible mushrooms as producers of amylases. Food Chemistry, v. 4, n. 3, p. 203-211, 1979.

FEDATTO, L. M. Caracterização de proteases extracelulares produzidas por Xylella fastidiosa de citros e videira. Piracicaba,
2004. Dissertação - (Mestrado), Universidade de São Paulo, Curso Interunidades, ESALQ/CENA-USP.

FIDALGO, O.; FIDALGO, M. E. P. K. Dicionário Micológico. Rickia, v. 2, supl., p. 12-32, 1967.

FRAZIER, W. C.; WESTHOFF, D. C. Food Microbiology. 4 ed. New York: McGraw-Hill International Edition, 1988. p. 390-397.

KOTABLA, F.; POUZAR, K. Preliminary results on the staining of spores and other structures of Homobasidiomycetes in cotton blue and its importance for taxonomy. Feddas Report, v. 69, n. 2, p. 131-142, 1964.

MANACHINI, P. L.; FORTINA, M. G.; PARINI, C. Purification and properties of an endopolygalacturonase produced by Rhizopus stolonifer. Biotechnology Letters, v. 9, n. 3, p. 219-224, 1987.

MARTIN, G. W. Three new Heterobasidiomycetes. Mycologia, v. 25, p. 261-265, 1934.

MATHEUS, D. C.; OKINO, L. K. Utilização de basidiomicetos em processos biotecnológicos. In: BONONI, V. L. R.; GRANDI, R. A. P. (Eds.). Zigomicetos, Basidiomicetos e Deuteromicetos: noções básicas de taxonomia e aplicações biotecnológicas. São Paulo: Instituto de Botânica, 1998. p. 107-139.

MULLINGS, R. Measurement of saccharification by cellulases. Enzyme and Microbial Technology, v. 7, p. 586-591, 1985.

NIELSEN, R. I.; OXENBOLL, K. Enzymes from fungi: their technology and uses. Mycologist, p. 69-71, 1998.

ORBERG, P. K. Studies on cellulases production from annual ryegrass straw by Trichoderma reesei. Oregon, 1981. Dissertação - (Mestrado), Oregon State University.

RAO, M. B. et al. Molecular and biotechnological aspects of microbial proteases. Microbiology and Molecular Biology Reviews, v. 62, n. 3, p. 597-635, 1998.

REDDY, N. S.; NIMMAGADDA, A.; RAO, K. R. S. An overview of the microbial $\alpha$-amylase family. African Journal of Biotechnology, v. 2, n. 12, p. 645-648, 2003.

ROBLES, A. et al. Phenol-oxidase (laccase) activity in strains of the Hyphomycete Chalara paradoxa isolated from olive mill wastewater disposal ponds. Enzyme and Microbial Technology, v. 26, n. 7, p. 484-490, 2000.

SAID, S.; PIETRO, R. Enzimas de interesse industrial e biotecnológico. Rio de Janeiro: Eventos Ed., 2002. 121 p.

SAPARRAT, M. C. N. et al. Screening for ligninolytic enzymes in autochthonous fungal strains from Argentina isolated from different substrata. Revista Iberoamericana de Micologia, v. 19, p. 181-185, 2002.

SILVEIRA, V. D. Micologia. 5 ed. Rio de Janeiro: Âmbito Cultural, 1995. $336 \mathrm{p}$.

SINDHU, G. S. et al. Strain improvement for the production of a thermostable $\alpha$-amylase. Enzyme and Microbial Technology, v. 21, n. 7, p. 525-530, 1997.

SIQUEIRA, E. M. A.; MIZUTA, K.; GIGLIO, J. R. Pycnoporus sanguineus: a novel source of $\alpha$-amylase. Mycologycal Research, v. 101, n. 2, p. 188-190, 1997.

SILVEIRA, V. D. Micologia. 5 ed. Rio de Janeiro: Âmbito Cultural, 1995. $336 \mathrm{p}$.

SINGER, R. The Agaricales in Modern Taxonomy. 4 ed. Germany: Koeltz Scientific Books, 1986. 981 p.

SNELL, W. H.; DICK, E. A. A glossary of mycology. Cambridge: Harvard University Press, 1957. 170 p. 
SOUSA, M. A. O gênero Phellinus Otréler (Hymenomycetes) na Amazônia Brasileira. Manaus, 1980. 190 p. Tese - (Doutorado), Instituto Nacional de Pesquisas da Amazônia, Universidade Federal do Amazonas.

SOUZA, J. V. B. et al. Screening of fungal strains for pectinolytic activity: endopolygalacturonase production by Paecilomyces clavisporus 2A.UMIDA.1. Process Biochemistry, v. 39, n. 4, p. 455-458, 2003.

STURION, G. L; RANZANI, M. R. T. C. Produção do cogumelo comestível Pleurotus: Opção promissora, especialmente na região do Vale do Ribeira. Série Produtor Rural, n. 2, p. 44, 1997.
TEIXEIRA, M. F. S. Obtenção de espécies de Aspergillus e Penicillium termofílicas e termotolerantes na Amazônia e caracterização de suas enzimas de interesse na indústria de alimentos. Manaus, 1994, 85 p. Dissertação - (Mestrado), Instituto Nacional de Pesquisas da Amazônia, Universidade Federal do Amazonas.

VALMASEDA, M.; ALMENDROS, G.; MARTÍNEZ, A. T. Substratedependent degradation patterns in the decay of wheat straw and beech wood by ligninolytic fungi. Applied Microbiology and Biotechnology, v. 33, p. 481-484, 1990.

WHITAKER, J. R. Principles of enzymology for the food science. 2 ed. New York: Marcel Dekker, Inc., 1994. 625 p. 